\title{
GAYA HIDUP HEDONISME DALAM KONSUMSI DITINJAU DARI PERSPEKTIF EKONOMI ISLAM (Studi Pada Mahasiswi Jurusan Ekonomi Islam IAIN Kota Bengkulu)
}

\author{
Mardian Suryani, Siti Achira \\ Universitas Islam Indonesia (UII), Yogyakarta, Indonesia \\ Email : Mardiansuryani1@gmail.com,siti.achiria@uii.ac.id
}

\begin{abstract}
A hedonic lifestyle is a lifestyle that prioritizes mere pleasure. Many individuals have a hedonic lifestyle, including students. The purpose of this study is to find out what are the factors that lead to the hedonism lifestyle of the students of the Islamic Economics Department of IAIN, Bengkulu City, and how to review the Islamic Economy on Hedonism Behavior. This research is a qualitative research, with a phenomenology approach. Using a purposive sampling technique involving the 4th semester students and 6th semester students. The results showed that the factors that influence the lifestyle of hedois for female students in economics majors in general are divided into two, namely (internal), and (external) factors. Islam does not justify a hedonic lifestyle because it will cause harm to individuals and society, where a lifestyle like this will lead to a spree in which Islam teaches life according to needs (maslahah) a hedonic lifestyle will give youth a disadvantage, in this case college student.
\end{abstract}

Keywords: Lifestyle, Hedonism, Consumption, Islamic Economics.

Abstrak: Gaya hidup hedonis merupakan pola hidup yang mengutamakan kesenangan semata. Banyak dijumpai individu memiliki gaya hidup hedonis, termasuk mahasiswa. Tujuan penelitian ini untuk mengetahui apa saja faktor-faktor yang menyebabkan Gaya hidup hedonisme mahasiswa Jurusan Ekonomi Islam IAIN Kota Bengkulu, dan bagaimana tinjauan Ekonomi Islam tentang Prilaku Hedonisme. Penelitian ini merupakan penelitian kualitatif, dengan pendekatan Fenomenologi. Menggunakan teknik purposive sampling dengan melibatkan mahasiswa semester 4 dan mahasiswa semester 6. Hasil penelitian menunjukan bahwa faktor faktor yang mempengaruhi gaya hidup hedois pada mahasiswi jurusan ekonomi secara umum terbagi menjadi dua yaitu faktor (internal), dan faktor (eksternal). Islam tidak membenarkan gaya hidup hedonis sebab akan menimbulkan mudharat bagi individu maupun masyarakat, dimana gaya hidup seperti ini akan menyebabkan adanya sifat berfoya-foya dimana Islam sebaliknya mengajarkan hidup sesuai kebutuhan (maslahah) gaya hidup hedonis akan memberikan mudharat bagi para pemuda, dalam hal ini mahasiswa.

Kata kunci: Gaya Hidup, Hedonisme, Konsumsi, Ekonomi Islam

\section{A. PENDAHULUAN}

Sistem ekonomi mencakup pembahasan tentang tata cara mengelolah sumber daya alam dan perolehan harta kekayaan dan pemanfaatannya baik untuk kegiatan produksi, distribusi, maupun konsumsi. ${ }^{1} \quad$ Dalam konsumsi Islam diajarkan untuk mengutamakan kebutuhan ketimbang keinginan yang mana kebutuhan dalam Islam didasarkan pada maslahah. Di mana setiap orang

\footnotetext{
${ }^{1}$ Ali Yafie Dkk, Menggagas Ekonomi Islam, (Jakarta: PT. Umitoha Ukhuwah Grafika, 2002), hlm.5
}

harus memenuhi kebutuhan hidupnya baik sandang, pangan dan papan. Kebutuhan dalam Islam disebut daruriyat, hajiyat, dan tahsiniyat.

Namun kebanyakan yang terjadi pada konsumen saat ini adalah terkadang sulit membedakan antara kebutuhan (need/hajah) dengan keinginan (want/raghbah). Tuntutan gaya hidup pada saat ini, menjadikan manusia mengarah kepada sikap pemborosan yang tidak terhentikan, kerena diliputi oleh pemikiran untuk berkonsumsi secara 
terus menerus. Dalam memenuhi kebutuhan peran keinginan lebih besar berpengaruh terhadap keputusan dalam memenuhi kebutuhan.

Dalam perspektif ekonomi syari'ah konsumsi bukan hanya sekedar memenuhi kebutuhan individu, sebagai konsumen dalam rangkah memenuhi perintah Allah, akan tetapi lebih jauh berimplikasi terhadap kesadaran berkenaan dengan kebutuhan orang lain. Oleh karenanya dalam konteks adanya keizinan untuk mengonsumsi rezeki yang diberikan Allah SWT, sekaligus terpikul tanggung jawab untuk memberikan perhatian terhadap keperluan hidup orang-orang yang tidak punya. baik yang tidak meminta maupun yang meminta, bahkan untuk orang-orang yang sengsara dan fakir miskin. ${ }^{2}$

Islam memposisikan aktivitas ekonomi sebagai salah satu aspek yang penting untuk mendapatkan falah, dan karenanya kegiatan ekonomi perlu di control agar berjalan sesuai dengan ajaran Islam secara keseluruhan. Falah, kehidupan yang mulia dan sejahtera di dunia dan akhirat, dapat terwujud apabila terpenuhi kebutuhan-kebutuhan hidup manusia secara seimbang. Tercukupinya kebutuhan manusia akan memberikan

\footnotetext{
${ }^{2}$ Amirul Naruddin, Dari Mana Sumber Hartamu (Ranungan tentang bisnis Islam dan ekonomi Syari'ah). (Sumatra: Erlangga, 2002), hlm.313-315
}

dampak yang disebut dengan maslahah. Maslahah adalah segala bentuk keadaan, baik material maupun non material, yang mampu meningkatkan kedudukan manusia yang paling mulia.

Terutama bagi mereka yang sedang menuntuk ilmu pengetahuan pada Fakultas Ekonomi dan Bisnis Islam, khususnya mahasiswa Jurusan Ekonomi dan Islam. Meskipun mereka memiliki pengetahuan tentang Islam, dan berada dilingkungan yang serba Islami, mulai dari Universitas, Fakultas serta Jurusannya, bahkan mempelajari gaya hidup dan perekonomian yang dipadukan dengan ajaran-ajaran Islam, sebagai panut ajaran yang dibawakan oleh Muhammab saw, namun tidak menjadi sebuah jaminan bahwa mahasiswi Ekonomi Islam untuk tidak terjebak dalam prilaku negative seperti prilaku Hedonisme. Sebagai kaum terpelajar, yang harus selektif dalam menyikapi perubahan budaya baru, yang cendrung hidup berfoya-foya, bermewah-mewahan, demi memenuhi kesenangan dan hasrat yang tanpa batas.

Menurut Yuniar Dwi Sartika dan Hudaniah dalam Penelitiannya yang berjudul "Gaya Hidup Hedonis dan Itensi Korupsi pada Mahasiswa Pengurus Lembaga Intra Kampus” (2018), menunjukan adanya hubungan positif yang signifikan antara gaya hidup 
hedonis dengan itensi korupsi pada mahasiswa pengurus lembaga intra. Semakin tinggi gaya hidup hedonis mahasiswa, akan semakin tinggi pula itensi korupsinya. ${ }^{3}$ Masrukhi (2013) menyatakan bahwa $10 \%$ mahasiswa merupakan mahasiswa idealis sedangkan 90\% merupakan mahasiswa hedonis. Berdasarkan pernyataan tersebut membuktikan bahwa pada saat ini perilaku hedonis semakin marak terjadi dikalangan mahasiswa. Berdasarkan penelitian yang dilakukan oleh Nadzir (2015) diketahui bahwa kegiatan yang sering dilakukan mahasiswa adalah jalanjalan ke mall (24\%), nongkrong di cafe (24\%), nonton ke bioskop (17\%), pergi ke took buku (10\%), karaoke dengan teman-teman (9\%), belajar memahami materi dari dosen (7\%), bermain game $(5 \%)$ dan pergi ke perpustakaan hanya (3\%). Hal ini menunjukkan bahwa mahasiswa lebih mengutamakan kesenangan hidup daripada kegiatan belajar, karena waktu luang yang mereka miliki lebih banyak dihabiskan untuk bersenang-senang. Perilaku mahasiswa yang memiliki gaya hidup hedonis ini ditunjukkan dengan mencari kesenangan dengan berusaha untuk selalu tampil

${ }^{3}$ Yuniar Dwi Sartika dan Hudaniah, Gaya Hidup Hedonis dan Itensi Korupsi pada Mahasiswa Pengurus Lembaga Intra Kampus, Jurnal Ilmiah Pisikologi Terapan, Malang: Vol. 06, No. 02, Agustus 2018, hlm. 16 trendy, senang memiliki barang-barang mewah dengan merk yang prestisius, senang nongkrong di café atau mall dan makan makanan di restoran cepat saji. ${ }^{4}$

Tercatat jumlah mahasiswa $\mathrm{S} 1$ Jurusan Ekonomi Islam IAIN Kota Bengkulu angkatan 2015 hingga 2018 sebanyak 814 orang dengan jumlah dan visi misi yang disusun oleh Jurusan Ekonomi Islam salah satunya yaitu Menghasilkan lulusan yang berkualitas secara akademis dan moral serta berorientasi global dalam bidang ekonomi dan manajemen syariah. Oleh karena itu peneliti tertarik membuat penelitian tentang gaya hidup hedonism dalam konsumsi ditinjau dari perspektif ekonomi islam (pada mahasiswa jurusan Ekonomi Islam IAIN Bengkulu).

\section{B. LANDASAN TEORI}

\section{Gaya Hidup}

Gaya hidup (life style) merupakan gaya hidup yang berkaitan dengan bagaimana sesorang menghabiskan waktunya, untuk apa yang penting pertimbangkan pada minat dan lingkungannya, dan apa ynag orang pikirkan tentang diri sendiri dan lingkungan sekitar. ${ }^{5}$

\footnotetext{
${ }^{4}$ Nadzir, M. Psychological meaning of money dengan gaya hidup hedonis remaja di kota Malang. Skripsi. Malang: Fakultas Psikologi Universitas Muhammadiyah Malang, 2015. hlm. 7

${ }^{5}$ Donni Juni Priansa, Prilaku Konsumen dalam Persaingan Bisnis Kontemporer, (Bandung: Alfabeta, 2017), hlm. 185
} 
a. Jenis Gaya Hidup Konsumen

Gaya hidup konsumen terdiri dari berbagai macam jenis, Secara umum, jenis gaya hidup konsumen adalah sebagai berikut:

\section{1) Gaya Hidup Mandiri}

Yaitu kemampuan untuk hidup tanpa bergantung dengan lain,

2) Gaya Hidup Modern

Yaitu dimana keinginan akan penggunaan teknologi dan informasi digital.

3) Gaya Hidup sehat

Gaya hidup ini adalah gaya hidup yang tepat untuk dijalani, hidup dengan lingkungan, pola makan, dan fikiran yang sehat yang dapat memberikan hasil yang baik dan fositif.

4) Gaya Hidup Hedonis

Gaya hidup hedonisme merupakan suatu pola fikir yang aktivitas untuk mencari kesengan hidup semata, seperti lebih banyak menghabiskan waktu diluar rumah, lebih banyak bermain dan selalu ingin jadi pusat perhatian.

5) Gaya Hidup Bebas

Gaya hidup ini dimana dalam menjalankan kehidupan seseorang mengikuti kehendak hati tanpa terikat oleh aturan yang ada dimasyarakat.
6) Gaya Hidup Hemat.

Hidup sesuai dengan kemampuan, konsumen yang mampu berfikir secara ketat terkait pengelolahan uangnya. ${ }^{6}$

\section{b. Gaya Hidup Hedonisme}

Teori hedonistic menyatakan bahwa segala perbuatan manusia, baik di sadari ataupun tanpa disadari, baik timbul dari kekuatan dalam ataupun luar pada dasarnya memiliki tujuan yang sama, yaitu mencari hal-hal yang menyenangkan dan menghindar dari hal-hal yang menyakitkan. Hedonis merupakan salah satu dari teori motivational yang cocok dengan prinsip arah tujuan yang dianggap paling menarik. ${ }^{7}$

\section{Konsumsi dalam Islam}

Konsumsi merupakan kegiatan ekonomi yang penting, bahkan dianggap paling penting dalam mata rantai kegiatan ekonomi, yaitu produksi-konsumsi-distribusi.

Kegiatan produksi ada karena ada yang mengonsumsi, kegiatan konsumsi ada karena ada yang memproduksi, dan kegiatan distribusi muncul karena ada gap atau jarak

${ }^{6}$ Ibid, hlm. 185

${ }^{7}$ Chiristina Whidya Utama, Manajemen Ritel Strategi dan Implementasi Operasional Bisnis Ritel Modern di Indonesia, (Jakarta: Salemba Empat, 2012), hlm. 48 
antara konsumsi dan produksi.

Berdasarkan kamus besar bahasa Indonesia, konsumsi diartikan sebagai pemakaian barang hasil produksi berupa pakaian, makanan dan lain sebagainya. Atau barang-barang yang langsung memenuhi kebutuhan hidup manusia. Dengan kata lain, konsumsi adalah suatu kegiatan manusia yang secara langsung menggunakan barang dan jasa untuk memenuhi kebutuhannya dengan tujuan untuk memperoleh kepuasan yang berakibat mengurangi ataupun menghabiskan nilai guna suatu barang atau jasa. ${ }^{8}$ Adapun konsumsi Islam adalah kegiatan memanfaatkan atau menghabiskan barang atau jasa untuk memenuhi kebutuhan manusia dalam upaya menjaga kelangsungan hidup dengan ketentuan syariat. ${ }^{9}$

Dari beberapa pengertian konsumsi diatas dapat diartikan bahwa definisi konsumsi dalam Islam adalah suatu bentuk prilaku manusia dalam menggunakan dan menfaatkan barang dan jasa untuk memenuhi kebutuhan hidup dengan secara tidak berlebihlebihan dan berdasarkan kepada

${ }^{8}$ Dewan Pengurus Nasional FORDEBI dan ADESY, Ekonomi dan Bisnis Islam: Seri Konsep dan Aplikasi Ekonomi dan Bisnis Islam, Cet. 2, (Depok: PT RajaGrafindo Persada, 2017), hlm. 317

${ }^{9}$ Vinna Sri Yuniarti, Ekonomi Mikro Syariah, (Bandung: CV Pustaka Setia, 2016), hlm.77-78 prinsip-prinsip syari'ah. Konsumsi bagi seorang muslim hanya sekedar sarana untuk beribadah kepada Allah SWT.

a. Konsep Islam Tentang Kebutuhan

Dalam perspektif Islam kebutuhan ditentukan oleh Maslahah, dimana tujuan shari'ah harus dapat menentukan tujuan prilaku konsumen. ${ }^{10}$ Konsumsi pada dasarnya dibangun atas dua hal, yaitu kebutuhan, dan kegunaan. Karena secara rasional seseorang tidak pernah mengonsumsi suatu barang apabila dia tidak membutuhkannya sekaligus mendapatkan manfaat darinya.

1) Kebutuhan (hajat)

Kebutuhan manusia terkait dengan segala sesuatu yang harus dipenuhi, dalam perspektif ekonomi Islam, semua barang dan jasa yang membawa pengaruh pada kemaslahatan disebut dengan kebutuhan manusia. $^{11}$

2) Kegunaan (manfaat)

Maslahah suatu barang atau jasa yang terdiri dari manfaat dan berkah, manfaat bukan hanya

\footnotetext{
${ }^{10}$ Manan, Teori dan Praktek Ekonomi Islam, (Yogyakarta: PT. Dana Bhakti Prima Yasa, 1996), hlm. 44

${ }^{11}$ Rozalinda, Ekonomi Islam Teori dan Aplikasinya pada Aktivitas Ekonomi, (Jakarta: PT Raja Grafindo Persada, 2014), hlm. 104-105
} 
sekedar kenikmatan yang bisa dirasakan oleh anggota tubuh manusia, namun lebih dari itu manfaat merupakan cermin dari terwujudnya kemaslahatan hakiki dan nilai guna maksimal yang tidak berpotensi mendatangkan dampak negativ dikemudian hari. $^{12}$ Maslahah yang diperoleh konsumen ketika membeli barang: Manfaat material, manfaat fisik dan psikis, manfaat intelektual, (intra generation), manfaat jangka panjang. ${ }^{13}$

b. Prinsip-Prinsip Dasar Konsumsi Menurut Abdul Manna (Bustanuddin, 2006), prinsip prilaku konsumsi seorang Muslim adalah sebagai berikut.

1) Prinsip Keadilan

Prinsip ini mengandung arti mencari rezeki yang halal dan tidak dilarang hukum. Konsumen tidak boleh menimbulkan kezaliman, berada dalam koridor aturan atau hukum agama, serta menjunjung

${ }^{12}$ Abdul Rahim, Ekonomi Islam Perspektif Muhammad SAW, (Jember: Stain Jember Press, 2013), hlm. 96

${ }^{13}$ Pusat Pengkajian dan Pengembangan Ekonomi Islam (P3EI), Ekonomi Islam, (Jakarta: PT Raja Grafindo Persada, 2014), hlm. 143-144 tinggi kepantasan atau kebaikan (halalan toyyiban). ${ }^{14}$

2) Prinsip Kebersihan

Prinsip ini mengatur tentang makanan dan minuman yang dikonsumsi harus baik atau cocok untuk dikonsumsi, tidak kotor ataupun menjijikkan sehingga merusak selera, karena itu, tidak semua yang diperkenankan boleh dimakan dan diminum. ${ }^{15}$

3) Prinsip Kesederhanaan

Prinsip ini mengatur manusia mengenai makanan dan minuman adalah sikap tidak berlebih-lebihan, yang berarti jangan makan secara berlebihan. $^{16}$ Dalam islam menganjurkan suatu cara konsumsi yang moderat, adil dan proposional. Intinya dalam islam konsumsi harus diarahkan secara benar, agar keadilan dan kesetaraan untuk semua bisa tercipta. $^{17}$ hlm. 80-81

${ }^{14}$ Vinna Sri Yuniarti, Ekonomi Mikro...,

${ }^{15}$ Eko Supriyanto, Ekonomi Islam, (Yogyakarta: Graha Ilmu, 2005), hlm. 94

${ }^{16}$ Manan, Teori dan Praktek Ekonomi..., hlm. 74

${ }^{17}$ Abdul Rahim, Ekonomi Islam Perspektif Muhammad SAW..., hlm. 100 
4) Prinsip kemurahan hati

Sifat konsumsi manusia juga harus dilandasi oleh kemurahan hati. Maksudnya, jika memang masih banyak orang yang kekurangan makanan dan minuman, seorang muslim hendaklah menyisihkan makanan yang ada padanya kemudian memberikannya kepada mereka yang sangat membutuhkan. ${ }^{18}$ Dengan menjalankan perintah Islam tidak akan ada bahaya maupun dosa ketika memakan dan meminum makanan halal. ${ }^{19}$

5) Prinsip Moralitas

Pada akhirnya konsumsi seorang muslim harus dibingkai oleh moralitas sehingga tidak sematamata memenuhi segala kebutuhan $^{20}$ Seorang muslim diajarkan untuk menyebut nama Allah sebelum makan dan sesudah dan menyatakan trimakasih kepada-Nya setelah makan. $^{21}$

hlm.82

${ }^{18}$ Vinna Sri Yuniarti, Ekonomi Mikro..., hlm. 47

${ }^{19}$ Manan, Teori dan Praktek Ekonomi..., hlm. 82

${ }^{20}$ Vinna Sri Yuniarti, Ekonomi Mikro...,

${ }^{21}$ Eko Supriyanto, Ekonomi Islam..., hlm. 94

\section{METODE PENELITIAN}

Metode penelitian ini menggunakan penelitian kualitatif dengan pendekatan fenomenologis dan normatif. Digunakannya pendekatan fenomenologis karena berhubungan langsung dengan gejala-gejala yang mencul di sekitar lingkungan manusia, pada penelitian ini penulis mencoba untuk memahami makna peristiwa dan iteraksi pada orang-orang dalam situasi tertentu yang bermaksud menemukan fakta.

Penelitian ini dilakukan di Institut Agama Islam Negeri Bengkulu. Sumber data yang digunakan adalah data primer yaitu data didapatkan melalui wawancara dan pengamatan langsung dilapangan, Adapun penentuan Informan dalam penelitian ini peneliti menggunakan teknik purposive. Dengan kriteria atau ciri-ciri: mahasiswa semester 4 angkatan tahun 2016 dan mahasiswa semester 6 angkatan tahun 2017, adapun informen merujuk kepada mahasiswa angkatan semester 4 dan 6 karena pada semester ini telah dipelajari Prilaku Konsumsi Ekonomi Islam sehingga mereka memahami bagaimana gaya hidup dalam berkonsumsi yang di ajurkan dalam Islam. Adapun data sekunder yaitu data yang diperoleh dari dokumen-dokumen, buku-buku, artikel, jurnal yang berkaitan dengan tema penelitian. 
Dengan menggunakan metode pengumpulan data observasi, wawancara, dokumentasi, dan reteratur review (Studi Pustaka). Adapun teknik pengumpulan data, yaitu: pengumpulan data, reduksi data, penyajian data, dan penarikan kesimpulan.

\section{HASIL DAN PEMBAHASAN}

Tujuan dari penelitian ini adalah untuk mengetahui faktor-faktor yang mempengaruhi gaya hidup hedonisme mahasiwi Jurusan Ekonomi Islam, serta bagaimana tinjauan ekonomi Islam tentang Gaya Hidup hedonisme. Adapun yang menjadi informen dari penelitian ini adalah Mahasiswi Ekonomi Islam angkatan tahun 2016 dan Mahasiswi Ekonomi Islam angkatan 2017.

Tabel 1 Rincian Jumlah Mahasiswa Ekonomi Islam Tahun 2019

No Tahun 2018 Ekonomi Islam

\begin{tabular}{llc}
\hline 1 & Angkatan 2015 & 229 \\
\hline 2 & Angkatan 2016 & 217 \\
\hline 3 & Angkatan 2017 & 175 \\
\hline 4 & Angkatan 2018 & 193 \\
\hline Jumlah : & 814
\end{tabular}

Sumber: Data FEBI, Juli 2019

Faktor-Faktor yang

Mempengaruhi Gaya Hidup Hedonisme Mahasiswa Jurusan Ekonomi Islam. Berdasarkan kriteria maka di dapatkan subjek sebagai berikut:
Tabel 2 Informen Penelitan

\begin{tabular}{|c|c|c|c|c|}
\hline $\mathrm{N}$ & $\begin{array}{c}\text { Nama } \\
\text { Mahasi } \\
\text { swa }\end{array}$ & $\begin{array}{c}\text { Jns } \\
\text { Kelamin/ } \\
\text { umur }\end{array}$ & $\begin{array}{l}\text { Thn.A } \\
\text { ngkat } \\
\text { an }\end{array}$ & $\begin{array}{c}\text { Alam } \\
\text { at }\end{array}$ \\
\hline 1 & $\begin{array}{l}\text { Reza } \\
\text { Okta } \\
\text { Verani }\end{array}$ & $\mathrm{P} / 21$ & 2016 & $\begin{array}{c}\text { Desa } \\
\text { Cireb } \\
\text { on } \\
\text { Baru }\end{array}$ \\
\hline 2 & $\begin{array}{l}\text { Winda } \\
\text { Ika } \\
\text { Afriyan } \\
\text { ti }\end{array}$ & $\mathrm{P} / 21$ & 2016 & $\begin{array}{c}\text { Tanju } \\
\text { ng } \\
\text { Dala } \\
\text { m }\end{array}$ \\
\hline 3 & $\begin{array}{l}\text { Adian } \\
\text { Saputra }\end{array}$ & $\mathrm{L} / 21$ & 2016 & $\begin{array}{c}\text { Lubuk } \\
\text { Lingg } \\
\mathrm{au} \\
\end{array}$ \\
\hline 4 & Dilmita & $\mathrm{P} / 21$ & 2016 & $\begin{array}{c}\text { Desa } \\
\text { Ujung } \\
\text { Pulau } \\
\end{array}$ \\
\hline 5 & $\begin{array}{l}\text { M. } \\
\text { Hafidz }\end{array}$ & $\mathrm{L} / 21$ & 2016 & $\begin{array}{c}\text { Kepah } \\
\text { iang }\end{array}$ \\
\hline 6 & $\begin{array}{l}\text { Feri } \\
\text { Hendra } \\
\text { wan }\end{array}$ & $\mathrm{L} / 21$ & 2017 & $\begin{array}{c}\text { Jl. } \\
\text { Bukit } \\
\text { Beran } \\
\text { gin }\end{array}$ \\
\hline 7 & Farina & $\mathrm{P} / 21$ & 2017 & $\begin{array}{c}\text { Tanju } \\
\text { ng } \\
\text { Berin } \\
\text { gin }\end{array}$ \\
\hline 8 & $\begin{array}{l}\text { Benny } \\
\text { Setiawa } \\
\mathrm{n}\end{array}$ & $\mathrm{L} / 20$ & 2017 & Lagan \\
\hline 9 & $\begin{array}{l}\text { Eli } \\
\text { Ermaw } \\
\text { ati }\end{array}$ & $\mathrm{P} / 20$ & 2017 & $\begin{array}{c}\text { Desa } \\
\text { karan } \\
\mathrm{g} \\
\text { Anyar }\end{array}$ \\
\hline $\begin{array}{l}1 \\
0\end{array}$ & $\begin{array}{l}\text { Feti } \\
\text { Indriani }\end{array}$ & $\mathrm{P} / 19$ & 2017 & $\begin{array}{c}\text { Desa } \\
\text { Tanju } \\
\text { ng } \\
\text { Dala } \\
\text { m }\end{array}$ \\
\hline
\end{tabular}

Sumber data: Wawancara

Feti merupakan mahasiswi IAIN Kota Bengkulu Jurusan Ekonomi Islam, berasal dari desa karang anyar. Feti saat 
ini berusia 19 tahun. Ketika diwawancara dia menjawab pertanyaan berdasarkan kehidupannya. Menurut feti bahwa memakai pakaian bermerek bisa membuat dirinya percaya diri. Selain itu, nongkrong di tempat-tempat kekinian bisa mengurangi tingkat stress yang dialaminaya. Baginya gaya hidup hedonis sah-sah saja dilakukan oleh semua orang jika dia mampu untuk melakukannya. ${ }^{22}$ Jika diamati dalam akun sosial media yang dimilikinya dia sering memposting beberapa poto yang menunjukkan posisi di mana ia sedang nongkrong untuk menunjukkan tempat makan yang pernah ia coba.

Benny Setiawan, Feri Hendrawan memiliki gaya hidup hedon dalam hal nongkrong, mereka mengaku tugas kuliahnya akan cepat selesai jika ia mengerjakannya dengan nongkrong. Menurutnya nongkrong memberikan inspirasi tersendiri untuk tugasnya. Selain ini untuk barang-barang yang dimilikinya ada merek tertentu yang mereka sukai. ${ }^{23}$ Eli Ermawati, dilmita dan winda, menurut mereka Ketika sedang merasa bosan dengan aktivitas perkuliahan, mereka selalu menyempatkan diri untuk menghabiskan waktu di mall, untuk

\footnotetext{
${ }^{22}$ Wawancara mahasiswa Ekonomi Islam, Feti Indriani, 26 Juni 2019.

${ }^{23}$ Wawancara Beni Stiawan dan Feri Hendrawan, Mahasiswa Ekonomi Islam, 26 Juni 2019.
}

berbelanja, nongkrong atau sekedar bersenang-senang dengan teman-teman saya agar saya tidak merasa bosan. Jika diamati dari Intagram mereka, mereka sering memposting foto ketika mereka mencoba tempat-tempat makan atau tempat wisata baru. ${ }^{24}$

Reza dan Farina, berdasarkan wawancara menurut mereka, mereka sangat senang ketika nongkrong dengan teman-temannya di mall, hal itu mereka lakukan untuk meyenangkan dirinya ketika sedang merasa lelah dengan semua aktivitas yang dilakukan, walaupun mereka sedang tidak banyak kegiatan mereka juga sering ke mall hanya sekedar untuk nongkrong-nongkrong, melihatlihat itu membuat mereka menjadi bahagia. ${ }^{25}$ M. Hafidz dan Adian menurut mereka, Untuk dapat bergaul dengan teman-teman, mereka harus berpenampilan menarik agar bisa beradaptasi dengan lingkungan yang kekiniian sesuai dengan perkembangan zaman, menggunakan barang bermerek membuatnya menjadi percaya diri ditambah lagi jika barang tersebut keluaran terbaru dengan model yang kekinian bahan yang bagus sehingga nyaman saat menggunakannya, itu sangat

\footnotetext{
${ }^{24}$ Wawancara Winda Ika Afriyanti, Dilmita dan Eli Ermawati, Mahasiswa Ekonomi Islam, 25 Juni 2019

${ }^{25}$ Wawancara, Reza dan Farina, Mahasiswa Ekonomi Islam, 27 Juni 2019.
} 
meningkatkan kepercayaan diri. ${ }^{26}$ Hal ini sejalan dengan pendapat Amstrong, mengatakan bahwa gaya hidup hedonis merupakan suatu pola hidup yang aktivitasnya berorientasi pada mencari kesenangan, seperti lebih banyak menghabiskan waktu untuk hal-hal yang kurang bermanfaat, lebih banyak menghabiskan waktu untuk bermain, membeli barang-barang yang mahal yang disenangi, mengikute fasion-fasion terbaru, dan selalu ingin jadi pusat perhatian. $^{27}$

Faktor faktor yang mempengaruhi gaya hidup hedois pada mahasiswi jurusan ekonomi secara umum terbagi menjadi dua yaitu faktor (internal) yaitu faktor dari dalam diri yaitu untuk beradaptasi dengan lingkungan, agar merasa tidak bosan mereka memiliki keinginan untuk nongkring ditempattempat yang lagi hitz, belanja, bersenangsenang dan jalan-jalan di mall dengan temang (eksternal) pengaruh dari luar individu meniru fasion-fasion jaman sekarang, tinggal jauh dari orang tua sehingga mengontrol uang sendiri dan orang tua mendukung untuk berbelanja. Semua mahasiswa jurusan Ekonomi Islam mereka telah mempelajari bahkan memahami tentang konsumsi dalam

\footnotetext{
${ }^{26}$ Wawancara, M. Hafidz dan Adian, Mahasiswa Ekonomi Islam, 26 Juni 2019

${ }^{27}$ Chaney dan Bitta, Perilaku Konsumen. 1994. (Jakarta: Binarupa Aksara, 2000), hlm. 34
}

Islam tetapi karena faktor-faktor tersebut telah menjadi budaya secara terus menerus di generasi sekarang jadi mereka tidak bisa menghidari prilaku hedonis untuk dapat beradaptasi dengan dilingkungannya.

Islam mengajarkan agar manusia menjalani kehidupannya secara benar, sebagaimana yang telah diatur oleh Allah swt. Bahkan usaha untuk hidup secara benar dan menjalani hidup secara benar inilah yang menjadikan hidup seseorang bernilai tinggi. Ukuran baik dan buruk kehidupan sesungguhnya tidak diukur dari indikatorindikator lain melainkan dari sejauh mana seorang manusia berpegang teguh pada kebenaran. Teori nilai guna (utility) apabila dianalisis dari teori mashlahah, kepuasan bukan didasarkan atas banyaknya barang yang dikonsumsi tetapi didasarkan atas baik atau buruknya seseuatu itu terhadap diri dan lingkungannya. Jika mengonsumsi sesuatu mendatangkan kemafsadatan pada diri atau lingkungan maka tindakan itu harus ditinggalkan.

Dalam ekonomi Islam maslahah lebih objektif daripada konsep utility untuk menganalisis prilaku konsumen. Secara analisis konsep maslahah lebih mudah dimanipulasi daripada konsep utility. Meskipun maslahah tetap bersifat subjektif sepirti halnya utility, namun subjektifitasnya lebih jelas. Berikut ini 
beberapa keuntungan konsep maslahah meliputi: ${ }^{28}$

1. Maslahah Subjektif dalam arti bahwa justifikasi terbaik terhadap kebutuhan barang/jasa ditentukan berdasarkan kemaslahatan bagi diri. Maslahah tidak menafikan konsep subjektifitas halnya utuliti. Contohnya minuman alcohol bagi sebagian orang utility yang tinggi untuk memanaskan badap dan menghilangkan permasalahan tapi dalam konsep maslahah alcohol hanya menimbulkan kemudharatan.

2. Maslahah bagi setiap Individu selalu konsisten dengan maslahah sosial. Berbeda dengan utility, akan berbeda antara utility pribadi dan utility sosial karena tidak ada kriteria yang jelas dalam menentukan utility. Sebagai contoh bagi sebagian orang alcohol dan rokok mempunyai nilai utility tapi bagi kepentingan sisial alcohol dan rokok justru menimbulkan mudharat.

3. Konsep maslahah menaungi seluruh aktivitas ekonomi masyarakat, karena hal ini adalah tujuan konsumsi, produksi dan transaksi ekonomi lainnya. Sedangkan utility adalah tujuan utama konsumsi dan profit (laba) adalah tujuan produksi.

${ }^{28}$ Sumar'in, Ekonomi Islam Sebuah Pendekatan Ekonomi Mikro Perspektif Islam, (Yogyakarta: Graha Ilmu, 2014), hlm. 97
Islam tidak menyebut suatu standard of living tertentu dangan batas minimus atau maksimum bagi seseorang. Penetapan standard of living secara keseluruhan tergantung pada kebijaksanaan dan kesadaran individu. Yang menjadi prinsip dasar system ekonomi islam adalah bahwa setiap umat Islam harus mendapatkan paling tidak kebutuhan dasarnya. Jadi, dalam suatu masyarakat yang ada terjadi kemiskinan, kesengsaraan, dan kekurangan, tidak seorangpun yang diperbolehkan menikmati hidup nyaman sekalipun dia kaya, kecuali semua orang lain tercukupi kebutuhan dasarnya. Pada dasarnya Islam memang tidak memperbolehkan hidup bermewah-mewah bagi setiap muslim, kesederhanaan hidup merupakan prinsip Islam yang tidak boleh hilang dari ingatan dalam memilih suatu gaya hidup. $^{29}$

Dari pernyataan yang telah dipaparkan diatas dapat kita simpulkan bahwa yang termasuk batasan konsumsi dalam syariah adalah pelarangan israf (berlebih-lebihan). Pelaku israf diharamkan sekalipun komoditi yang dibelanjakan adalah halal, Islam memperbolehkan seorang Muslim untuk menikmati karunia kehidupan, selama itu

${ }^{29}$ Muhammad Sharif Chandhry, Sistem Ekonomi Islam: Prinsip Dasar, ( Jakarta: Kencana, 2012), hlm. 157 
masih dalam batas kewajaran. Islam tidak membenarkan gaya hidup hedonis sebab akan menimbulkan mudharat bagi individu maupun masyarakat, dimana gaya hidup seperti ini akan menyebabkan adanya sifat berfoya-foya dimana Islam sebaliknya mengajarkan hidup sesuai kebutuhan (maslahah) gaya hidup hedonis akan memberikan mudharat bagi para pemuda, dalam hal ini mahasiswa.

\section{E. KESIMPULAN}

Berdasarkan hasil penelitian dapat diketahui bahwa faktor faktor yang mempengaruhi gaya hidup hedois pada mahasiswi jurusan ekonomi secara umum terbagi menjadi dua yaitu faktor (internal) yaitu faktor dari dalam diri yaitu untuk beradaptasi dengan lingkungan, agar merasa tidak bosan mereka memiliki keinginan untuk nongkring ditempattempat yang lagi hitz, belanja, bersenangsenang dan jalan-jalan di mall dengan temang (eksternal) pengaruh dari luar individu meniru fasion-fasion jaman sekarang, tinggal jauh dari orang tua sehingga mengontrol uang sendiri dan orang tua mendukung untuk berbelanja. Islam tidak membenarkan gaya hidup hedonis sebab akan menimbulkan mudharat bagi individu maupun masyarakat, dimana gaya hidup seperti ini akan menyebabkan adanya sifat berfoya-foya dimana Islam sebaliknya mengajarkan hidup sesuai kebutuhan (maslahah) gaya hidup hedonis akan memberikan mudharat bagi para pemuda, dalam hal ini mahasiswa.

\section{DAFTAR PUSTAKA}

Chaney dan Bitta., 1994, Perilaku Konsumen. 1994. Jakarta: Binarupa Aksara.

Dewan Pengurus Nasional FORDEBI dan ADESY., 2017, Ekonomi dan Bisnis Islam: Seri Konsep dan Aplikasi Ekonomi dan Bisnis Islam, Cet. 2, Depok: PT RajaGrafindo Persada.

Dwi Sartika, Yuniar dan Hudaniah., 2018, "Gaya Hidup Hedonis dan Itensi Korupsi pada Mahasiswa Pengurus Lembaga Intra Kampus, Jurnal Ilmiah Pisikologi Terapan”, Malang: Vol. 06, No. 02, Agustus 2018.

Juni Priansa, Donni., 2017, Prilaku Konsumen dalam Persaingan Bisnis Kontemporer, Bandung: Alfabeta.

Manan., 1996, Teori dan Praktek Ekonomi Islam, Yogyakarta: PT. Dana Bhakti Prima Yasa.

Nadzir, M., 2015, "Psychological meaning of money dengan gaya hidup hedonis remaja di kota Malang". Malang: Fakultas Psikologi Universitas Muhammadiyah Malang, 2015.

Naruddin, Amirul., 2002, Dari Mana Sumber Hartamu (Ranungan tentang bisnis Islam dan ekonomi Syari'ah). Sumatra: Erlangga.

Pusat Pengkajian dan Pengembangan Ekonomi Islam (P3EI)., 2014, Ekonomi Islam, Jakarta: PT Raja Grafindo Persada.

Rahim, Abdul., 2013, Ekonomi Islam Perspektif Muhammad SAW, Jember: Stain Jember Press. 
Rozalinda., 2014, Ekonomi Islam Teori dan Aplikasinya pada Aktivitas Ekonomi, Jakarta: PT Raja Grafindo Persada.

Sharif Chandhry, Muhammad., 2012, Sistem Ekonomi Islam: Prinsip Dasar, Jakarta: Kencana.

Sumar'in., 2014, Ekonomi Islam Sebuah Pendekatan Ekonomi Mikro Perspektif Islam, Yogyakarta: Graha Ilmu.

Supriyanto, Eko., 2005, Ekonomi Islam, Yogyakarta: Graha Ilmu.

Sri Yuniarti, Vinna ., 2017, Ekonomi Mikro Syariah, Bandung: CV Pustaka Setia.

Whidya Utama, Chiristina., 2012, Manajemen Ritel Strategi dan Implementasi Operasional Bisnis
Ritel Modern di Indonesia, Jakarta: Salemba Empat.

Yafie, Ali Dkk., 2002, Menggagas Ekonomi Islam, Jakarta: PT. Umitoha Ukhuwah Grafika.

Wawancara mahasiswa Ekonomi Islam, Feti Indriani, 26 Juni 2019.

Wawancara Beni Stiawan dan Feri Hendrawan, Mahasiswa Ekonomi Islam, 26 Juni 2019.

Wawancara Winda Ika Afriyanti, Dilmita dan Eli Ermawati, Mahasiswa Ekonomi Islam, 25 Juni 2019.

Wawancara, Reza dan Farina, Mahasiswa Ekonomi Islam, 27 Juni 2019.

Wawancara, M. Hafidz dan Adian, Mahasiswa Ekonomi Islam,26 Juni 2019. 